\title{
ATELLIE
}

\section{Região Imediata de Dianópolis - Tocantins: interpretando suas atividades produtivas}

\author{
Surrounding areas of Dianópolis city, Tocantins State, \\ Brazil: understanding their productive activities
}

\section{Entorno de la ciudad de Dianópolis, estado de Tocantins, Brasil: comprensión de sus actividades productivas}

\author{
Roberta Mara de Oliveira Vergara \\ Universidade Federal do Tocantins - Câmpus Palmas \\ robertaoliveira@mail.uft.edu.br \\ Samuel Ferreira da Fonseca \\ Universidade Federal do Tocantins - Câmpus Palmas \\ fonsekageo@gmail.com \\ Nilton Marques de Oliveira \\ Universidade Federal do Tocantins - Câmpus Palmas \\ niltonmarques@mail.uft.edu.br
}

\begin{abstract}
Resumo
O objetivo deste artigo foi analisar o desenvolvimento da Região Imediata de Dianópolis (RID), sudeste do Tocantins. Adotou-se o Quociente Locacional (QL) em relação ao pessoal ocupado em empregos formais nos oito setores econômicos, destacando a agricultura. Para cálculo do QL das atividades produtivas, coletou-se dados secundários na base de dados do Ministério do Trabalho e Emprego, entre 2006 e 2016. E, analisou-se a dinâmica do Índice Firjan de Desenvolvimento Municipal (IFDM), relacionando os valores deste com o QL. Observou-se que somente os municípios de Almas, Aurora do Tocantins e Novo Alegre possuíam QL significativo para agropecuária, extração vegetal, caça e pesca, em 2006. Por outro lado, $10(71,4 \%)$ dos 14 municípios, possuíam QL significativo para Administração Pública em 2006, alterando para 11 (78,6\%) em 2016. O desempenho locacional indica o avanço das atividades agropecuárias em 50\% dos municípios da RID em 2016. O alto valor de QL para o referido setor em 2016 reflete os impactos positivos do projeto de irrigação Manoel Alves, inaugurado em 2008.
\end{abstract}

Palavras-chave: Desenvolvimento Regional, Região imediata de Dianópolis, Quociente locacional. 


\begin{abstract}
This paper aimed to analyze the development of the surrounding areas of Dianópolis city (SAD) at southeast of Tocantins State, Brazil. Location Quotient (LQ) related to the employees working in formal jobs at the eight economic sectors emphasizing on agriculture was used. To calculate the LQ of productive activities, secondary data were collected at the Brazilian Ministry of Labor and Employment database from 2006 to 2016. The dynamics of the Firjan Municipal Development Index (IFDM, Brazilian acronym) was analyzed, linking its values to LQ (Firjan is acronym for Federação das Indústrias do Estado do Rio de Janeiro (Industries Federation of the State of Rio de Janeiro). It was found that there was significant LQ for agriculture, vegetable extraction, hunting, and fishing only in the municipalities of Almas, Aurora do Tocantins, and Novo Alegre in 2006. On the other hand, there was significant LQ for Public Administration in ten (71.4\%) municipalities among fourteen municipalities in 2006, increasing to eleven (78.6\%) in 2016. Locational performance indicates the advance of agricultural activities in 50\% of SAD municipalities in 2016. The LQ high value in this sector in 2016 reflects the positive impacts of the Manoel Alves irrigation project implemented in 2008.

Keywords: Surrounding area of Dianópolis City. Location quotient. Regional Development.
\end{abstract}

\title{
Resumen
}

Este documento tuvo como objetivo analizar el desarrollo del entorno de la ciudad de Dianópolis (ED) en el sureste del estado de Tocantins, Brasil. Se utilizó el Cociente Locacional (CL) relacionado con los empleados que trabajan en empleos formales en los ocho sectores económicos con énfasis en la agricultura. Para calcular el CL de las actividades productivas, se recopilaron datos secundarios en la base de datos del Ministerio de Trabajo y Empleo de Brasil de 2006 a 2016. Se analizó la dinámica del Índice de Desarrollo Municipal de Firjan (IFDM, acrónimo de Brasil), vinculando sus valores a CL (Firjan es el acrónimo de Federação das Indústrias do Estado do Rio de Janeiro (Federación de Industrias del Estado de Rio de Janeiro). Se encontró que hubo CL importantes para la agricultura, la extracción de hortalizas, la caza y la pesca solo en los municipios de Almas, Aurora do Tocantins y Novo Alegre en 2006. Por otro lado, hubo CL significativos para la Administración Pública en diez (71.4\%) municipios entre catorce municipios en 2006, aumentando a once (78.6\%) en 2016. El desempeño local indica el avance de las actividades agrícolas en el 50\% de los municipios del entorno de la ciudad de Dianópolis (ED) en 2016. El alto valor de CL en este sector en 2016 refleja los impactos positivos del proyecto de riego Manoel Alves implementado en 2008.

Palabras clave: Cociente Locacional. Desarrollo regional. Entorno de la ciudad de Dianópolis.

\section{Introdução}

O desenvolvimento regional tem sido amplamente discutido, sobretudo no que tange a quantidade de variáveis relacionadas a este tema. Uma vez que o Produto Interno Bruto (PIB), historicamente relacionado ao desenvolvimento econômico, não comporta, por sua vez, todas as facetas do desenvolvimento (SIEDENBERG, 2003; FONSECA et al., 2016). Sendo assim, a abordagem do crescimento econômico requer um olhar para outras variáveis que compõem o espaço. 
Desde a compreensão do desenvolvimento como liberdade, proposto por Sen (2010), que pondera a relação entre o crescimento econômico e sua impossibilidade de ser, isoladamente, considerado desenvolvimento, à análise regional, são relevantes para compreender o avanço socioeconômico de um recorte geográfico. Para o autor além do econômico, fatores como: liberdade política, acesso à educação e saúde e direitos civis, mostram-se tão relevantes quanto à industrialização e progresso tecnológico para gerar desenvolvimento.

Sendo assim o recorte espacial escolhido para este trabalho foi a Região Imediata de Dianópolis (RID) do Estado do Tocantins, a qual abrange 14 municípios (IBGE, 2017). Esta área esteve durante décadas à margem do desenvolvimento experimentado pelo Estado de Goiás devido, sobretudo, ao seu isolamento físico, em relação às áreas daquele estado com maior potencial de crescimento. Com a criação do Estado do Tocantins em 1989 houve o rompimento do isolamento da Região, a partir da melhoria parcial da infra-estrutura rodoviária, abriu novas perspectivas de desenvolvimento para os municípios do Sudeste do Tocantins, que em sua grande maioria, apresentam baixos níveis de desenvolvimento econômico e social (SEPLAN, 2017).

Segundo SEPLAN (2017) pela análise dos cenários de crescimento dessa região, uma das alternativas estratégicas mais plausíveis e relevantes para o crescimento de longo prazo se sustenta na agropecuária e na agroindústria, a sua principal atividade econômica. Este ramo de atividade, é e será, ainda por muito tempo, a principal atividade a estruturar as relações econômicas e sociais da Região (SEPLAN, 2017). Por outro lado, a ideia de uma agricultura sustentável revela, antes de tudo, a crescente insatisfação com as condições em que se desenvolve a chamada "agricultura moderna". Indica o desejo de práticas que, simultaneamente, obtenham um aumento constante da produção em grande escala, conservem os recursos naturais e contribuam para melhorar as condições de vida da população regional.

Neste contexto, pode-se sugerir que a sustentabilidade do desenvolvimento da porção sudeste está vinculada muito diretamente à agricultura, sendo que tal vinculação deverá se fundamentar no desenvolvimento e expansão de uma agropecuária com maior produtividade, bem como atender as demandas sociais da população urbana e rural da região. Além disso, deve-se garantir o mínimo de impactos adversos no meio ambiente natural, o que implica pensar sobre as disponibilidades de recursos hídricos em quantidade e qualidade para suportar a expansão de tais atividades (SEPLAN, 2017).

Nessa direção, cabe destacar que vários trabalhos têm sido realizados no Tocantins com finalidade correlata, dentre estes, pode se mencionar Oliveira e Piffer (2018), que analisaram os fatores que determinam o perfil locacional de 22 municípios tocantinenses. Carvalho et al., (2018) pesquisaram a dinâmica do emprego formal em atividades produtivas na microrregião de Porto Nacional. Além destes, cabe pontuar uma análise mais específica na RID, realizada por Oliveira e Rodrigues (2017). Os autores verificaram a efetividade do projeto de irrigação Manoel Alves naquele recorte geográfico. 
O presente artigo buscou verificar os conceitos de estágios de crescimento regional estabelecidos por North (1977) e análise regional proposta por Isard (1960), Alves (2012) e Piffer (2012) bem como, suas complexas relações com a localização das atividades produtivas. Com isso, é possível entender a dinâmica regional em um recorte temporal de 10 anos, entre 2006 e 2016.

Isto posto, este trabalho está dividido em cinco partes: esta introdução; uma abordagem teórica, na qual se analisa algumas proposições inerentes ao desenvolvimento regional e crescimento econômico; a metodologia, descrevendo os procedimentos necessários, desde a aquisição dos dados à análise dos mesmos; resultados e discussões, propondo uma análise prévia dos resultados do QL e IFDM e as implicações destes na dinâmica econômica da região imediata de Dianópolis e; considerações finais, propondo uma reflexão a respeito das atividades econômicas e seu impacto direto na realidade socioespacial de cada ente federativo no recorte espacial supracitado.

\section{Desenvolvimento Regional: teoria de base econômica e indicadores de análise regional}

Para North (1977) os estágios que as regiões percorrem no curso do seu desenvolvimento, seguem uma lógica bem distinta:

1 - Na primeira fase, no trajeto econômico da maior parte das regiões, inicia-se o trabalho dependente da economia de subsistência, existindo pouco investimento ou comércio. Nesta fase, a população elementar concentra-se na agricultura e está situada de acordo com a distribuição de recursos naturais.

2 - O segundo momento é marcado pela melhoria nos aspectos logísticos, possibilitando a região desenvolver o comércio e especialização local. Logo, emerge uma nova camada populacional, a qual passa a gerir pequenas indústrias, de abrangência local, para os agricultores. Essa indústria, tem sua localização determinada por meio da camada básica. Por conseguinte, tal camada supre a indústria com matéria-prima e mão de obra.

3 - Ao passo que as relações comerciais ultrapassam a fronteira regional ocorre uma dinamização nas atividades agrícolas, alterando de pecuária extensiva à produção de cereais, posteriormente à fruticultura, à produção de laticínios e à horticultura.

4 - O crescimento demográfico associado à diminuição da produção agrícola, bem como de outras atividades primárias, força a região rumo à industrialização, introduzindo atividades secundárias em escala considerável. Os primeiros passos da industrialização firmam-se sobre produtos florestais e agrícolas, incluem atividades como processamento de alimentos, preparação de fibras têxteis e produção de artefatos de madeira. Se for adiante, a indústria dependerá de recursos naturais como, minérios e recursos energéticos. Caso exista energia elétrica em custos menores, torna-se possível a implantação de indústrias que dela necessitam em grandes quantidades (refinação de 
metais não-ferrosos, ligas de metais, aços especiais, abrasivos artificiais, etc.) como aconteceu na Noruega, Suíça, no Vale do Tennessee e no Vale do Rio Columbia.

5 - Atinge-se o estágio final do desenvolvimento regional quando a região se especializa em atividades terciárias, produzindo para exportação. Nesse estágio a região exporta capital, mão-de-obra qualificada e serviços especiais para as regiões menos desenvolvidas. Aos custos de transporte têm sido atribuído um papel fundamental no avanço através desses estágios sucessivos de desenvolvimento.

Considerando a grande extensão territorial brasileira, torna-se fator importante nos estágios de desenvolvimento a avaliação dos espaços regionais por possuírem diferenças marcantes e os indicadores econômicos e sociais ressaltam essas desigualdades nas estruturas produtivas. Guimarães Neto (1995), afirma que existe um grande diferencial na produtividade industrial e agrícola, bem como na concentração de segmentos estratégicos para a dinâmica da economia nacional. Entre os segmentos estratégicos, destaca-se a indústria de bens de capital e de bens de consumo não duráveis, em uma só região ou estado.

Begnini e Almeida (2016) consideram que por se tratar de uma formação multidimensional, o desenvolvimento regional perpassa diversos fatores econômicos, sociais, estruturais, educacionais e ambientais, entre outros, que podem influenciar a formação de determinada região. Para os autores o estudo do desenvolvimento, por tratar-se de um fenômeno multidimensional, ultrapassa as questões econômicas, envolvendo um conjunto de indicadores que estão ligados entre si. Essas variáveis estão ligadas a aspectos de bem-estar social e equidade, educação, estrutura e desempenho econômico, população e migração, meio ambiente e sustentabilidade.

\section{Teoria dos lugares centrais de Christaller e o Quociente locacional}

A teoria do lugar central, proposta por Walter Christaller, afirma que o desenvolvimento e o crescimento das áreas urbanas são dependentes do tipo de serviço fornecido ao seu entorno, isto é, as áreas de mercado de cada aglomeração urbana (OLIVEIRA e PIFFER, 2018). De acordo com Christaller (1966) a partir das áreas de influência a hierarquia das aglomerações no espaço regional é estabelecida. Para este autor, a centralidade é diretamente proporcional com a área de influência e as aglomerações na "órbita” de um centro.

Para Oliveira e Piffer (2018) entre as funções da centralidade estão: demonstrar a organização e a hierarquização do espaço, e apresentar o padrão de formação da rede de cidades e o papel da especialização de cada uma delas nessa rede. De acordo com esses autores, a determinação do crescimento e o desenvolvimento de um centro ou uma centralidade ocorrerá por meio da especialização em diversas atividades.

Na Figura 01, cada ponto representa um lugar central, e estes se escalonam em nível hierárquico dos menores, o centros $\mathrm{M}$ aos maiores o centros $\mathrm{G}$, de tal forma que é 
formada um rede hierárquica entre os centros, dado a capacidade que centros superiores tem de atrair os inferiores.

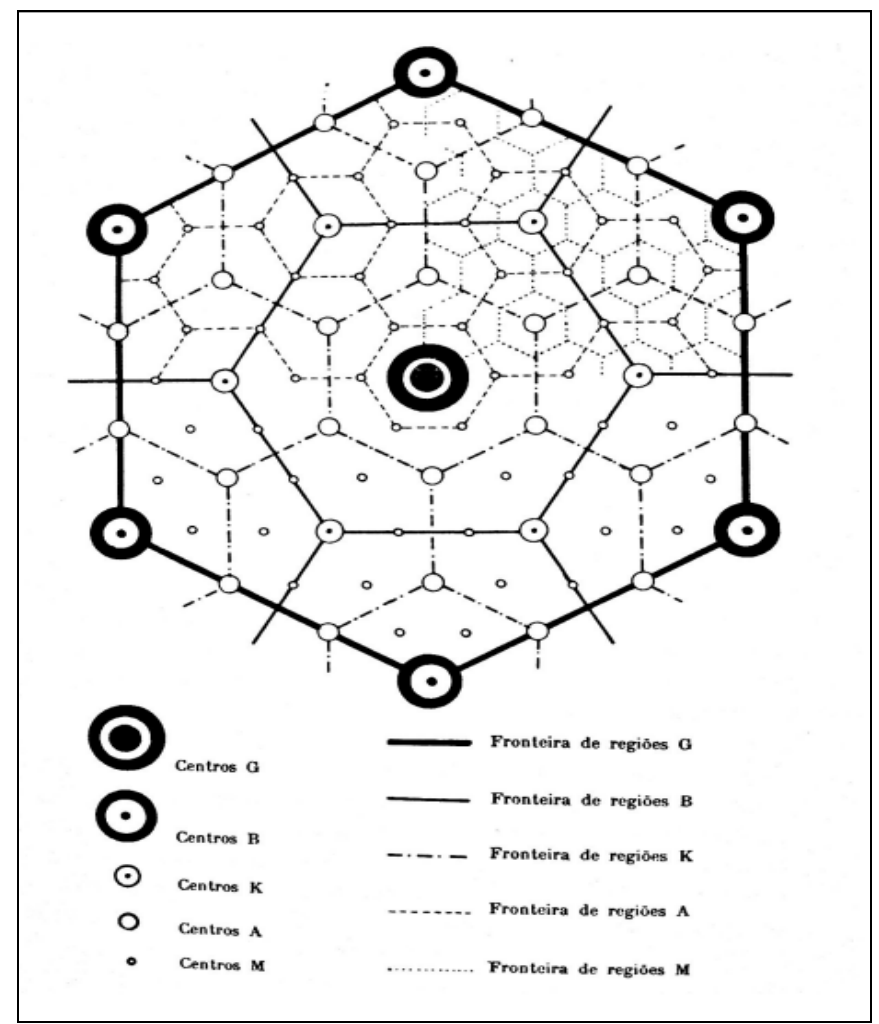

Figura 01. A paisagem dos lugares centrais.

Fonte: Lopes (1984) adaptado de Christaller (1966).

De acordo com Christaller (1966) dois conceitos também importantes a ser apresentados é o de alcance espacial mínimo (minimum range threshold) e alcance espacial máximo (maximum range). $\mathrm{O}$ primeiro, diz respeito a área do seu entorno; $\mathrm{o}$ segundo trata da abrangência de determinado lugar central em atrair consumidores em um determinado raio. Cabe ressaltar que Christaller entendia que todo núcleo de povoamento é encarado como lugar central uma vez fornecedor de bens e serviços, desconsiderando inclusive seu tamanho (OLIVEIRA et al., 2013).

A área de influência de uma aglomeração está para a sua polarização, em uma relação direta. Nesse caso, a densidade tem um papel preponderante para determinar a polarização (SATRASSBURG et al., 2014). Para esses autores, o avanço dos lugares centrais ou polos dependerá da densidade, seja ela populacional, de nível de renda e do número de atividades produtivas, em particular do setor terciário (no caso da teoria dos lugares centrais). Como o setor terciário depende dos dois primeiros elementos, seu 
crescimento é um indicador natural da capacidade de polarização dos centros urbanos. No caso, o setor terciário compõe as funções do lugar central, quais sejam: diversos tipos de comércio e serviços, desde serviços públicos, financeiros e bancários, especializados, grandes ou pequenos, religiosos e espirituais, de ensino em todos os níveis culturais, serviços de saúde, etc (STRASSBURG et al., 2014).

A teoria de Christaller se relaciona com o Quociente Locacional em uma relação direta, pois, lugares especializados, tendem a ser aqueles que se tornarão polarizadores (tomando a análise dos lugares centrais). Por outro lado, as áreas que apresentam valores não significativos desta métrica, tendem a estarem na "órbita" do lugar central identificado.

\section{Quociente Locacinoal e índice FIRJAN de desenvolvimento municipal}

Piffer (2012) ratifica a importância das atividades de base, como sendo aquelas que respondem pela geração de postos de empregos em outros setores econômicos. O autor baseia-se na Teoria de Base Econômica de North (1977), mostrando que as atividades podem ser estratificadas em básicas e não básicas. As primeiras são consideradas atividades motoras, as segundas, chamadas de residenciais, sendo que as últimas dependem de uma demanda endógena (PIFFER, 2012).

Alves (2012) apresenta o Quociente Locacional (QL) como o indicador mais utilizado em análises econômicas espaciais. Para este autor, o QL possibilita identificar a especialização de uma determinada localidade, além de ser o indicador mais utilizado na literatura. Este índice, possui certas vantagens para a análise regional, pois, apresenta o comportamento locacional de cada ramo produtivo, apontando setores mais especializados (potenciais) nas diferentes áreas (ALVES, 2012). Nestes termos, as atividades que apresentam valores de QL significativos, serão entendidas como potenciais para alavancar o desenvolvimento em determinada localidade.

Além das métricas apresentadas, o índice FIRJAN figura como um dos indicadores de desenvolvimento consistente. Possibilita verificar o crescimento econômico e social de um município, mostrando os avanços ano a ano do mesmo (FIRJAN, 2018). Este indicador torna possível averiguar periodicamente o desempenho de um município em relação a variáveis socioeconômicas, sendo vantajoso em relação ao IDH, que consiste em um recorte de dados de um referido ano, a cada dez anos (CÓCARO et al., 2016). Desta forma, neste trabalho busca-se associar o IFDM com os resultados do QL por setor econômico, com vistas a identificar atividades de especialização e sua relação com os municípios da RID. 


\section{Metodologia}

A metodologia utilizada considerou a observação dos aspectos socioeconômicos e demográficos da região sudeste do Tocantins, adotando-se o Quociente Locacional e o índice Firjan de desenvolvimento por município. O levantamento estatístico baseou-se nos dados do IBGE e SEPLAN, Ministério do Trabalho e Emprego (MTE) e Relação Anual de Informações Sociais (RAIS), com análise temporal de 2006 a 2016. Foram selecionados os oito ramos da economia, conforme classificado pelo IBGE: Indústria extrativa mineral; Agopecuária, extração vegetal, caça e pesca; Insdúdtria de transformação; Serviços industrais de utilidade pública; Construção civil; Serviços; Comércio e Adminstração pública (MTE/RAIS, 2016).

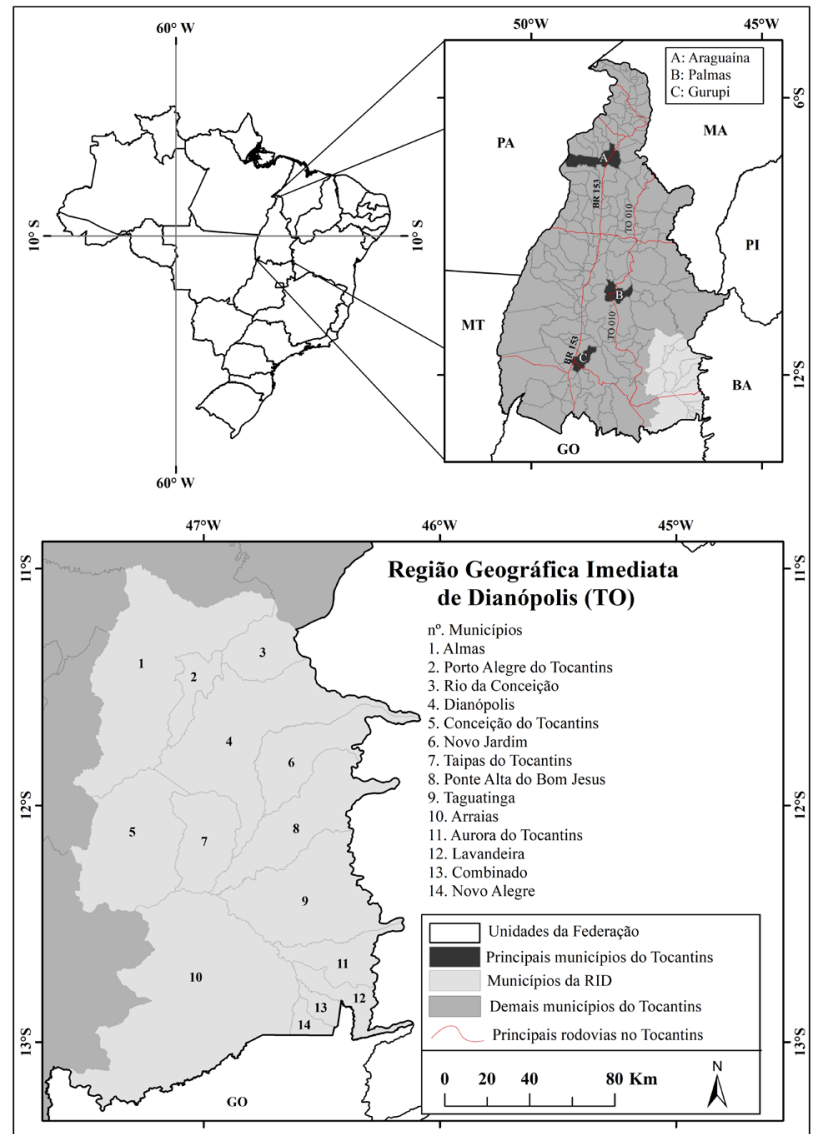

Figura 02: Mapa de localização da Região Imediata de Dianópolis, Estado do Tocantins. 
Dessa forma, com os índices dos Quocientes Locacionais e os dados socioeconômicos da RID, foi possível traçar um perfil das áreas em estudo e verificar em que ramo da atividade produtiva local é maior o desenvolvimento regional. A RID está situada na porção sudeste do Estado do Tocantins, abrange 14 municípios (Figura 02).

A população da RID consiste em 87.919 habitantes (IBGE, 2017), dos quais três municípios detêm $55 \%$ da população, sendo, Dianópolis (21.738) a maior população, seguido de Taguatinga (16.530) e Arraias (10.727) na terceira posição. Os demais municípios da RID agrupam população inferior a 10.000 habitantes (Tabela 01).

Tabela 01: População dos municípios da região imediata de Dianópolis (TO).

\begin{tabular}{c|c|c|c}
\hline \multirow{2}{*}{ Município } & \multicolumn{3}{|c}{ População } \\
\cline { 2 - 4 } & $\mathbf{2 0 0 0}$ & $\mathbf{2 0 1 0}$ & $\mathbf{2 0 1 7}$ \\
\hline Taipas do Tocantins & 1713 & 1945 & 2130 \\
Taguatinga & 13169 & 15051 & 16530 \\
Rio da Conceição & 1189 & 1714 & 2061 \\
Porto Alegre do Tocantins & 2393 & 2796 & 3102 \\
Ponte Alta do Bom Jesus & 4574 & 4544 & 4645 \\
Novo Jardim & 2151 & 2457 & 2697 \\
Novo Alegre & 2274 & 2286 & 2353 \\
Lavandeira & 1209 & 1605 & 1875 \\
Dianópolis & 15428 & 19112 & 21738 \\
Conceição do Tocantins & 4377 & 4182 & 4179 \\
Combinado & 4524 & 4669 & 4874 \\
Aurora do Tocantins & 3101 & 3446 & 3735 \\
Arraias & 10984 & 10645 & 10727 \\
Almas & 8474 & 7586 & 7273 \\
\hline
\end{tabular}

Fonte: Elaborado pelos autores com dados do IBGE, 2018. 
Com vistas a análise regional adotou-se o Quociente Locacional (QL), relacionado com o pessoal ocupado nos setores econômicos. Este indicador foi usado decorrente de sua simplicidade e robustez. A notação do QL pode ser exposta da seguinte forma, de acordo com (ALVES, 2012).

$$
\mathrm{QL}=(\text { POij } \div \text { POit }) /(\text { POtj } \div \text { POtt })
$$

Em que:

POij = Pessoas ocupadas no município i na atividade $\mathrm{j}$;

POit $=$ Pessoas ocupadas no município $\mathrm{i}$ em todas as atividades;

POtj $=$ Pessoas ocupadas na região imediata de Dianópolis na atividade j;

POtt $=$ Pessoas ocupadas na região imediata de Dianópolis em todas as atividades.

O QL pode ser interpretado em três níveis, conforme quadro abaixo:

Quadro 01: Interpretação do QL.

\begin{tabular}{|c|c|}
\hline \multicolumn{2}{|c|}{ Interpretação dos resultados do QL } \\
\hline $\mathrm{QL} \geq 1$ & localização significativa \\
\hline $0,50 \leq \mathrm{QL} \leq 0,99$ & localização média \\
\hline $\mathrm{QL} \leq 0,49$ & localização fraca \\
\hline
\end{tabular}

Fonte: Elaboração própria.

Estágios do crescimento econômico na RID e indicadores de desenvolvimento

Considerando os conceitos de North em relação aos estágios de desenvolvimento, para a região em estudo foram levantados os principais projetos implantados para o desenvolvimento agrícola com influência direta.

O Projeto de Irrigação conhecido como Manuel Alves, atende os municípios de Dianópolis e Porto Alegre do Tocantins, porção norte da área de estudo. Nesses entes federativos, com a implantação de sistemas de irrigação subsidiados pelo governo estadual, houve o impulsionamento do cultivo da fruticultura do abacaxi e melancia, que inclusive já alcançaram níveis de exportação animadores, e mamão, banana, coco-dabaía e maracujá. 
O Projeto da Barragem do Rio Manuel Alves abrange como área de influência os municípios de Almas, Porto Alegre, Dianópolis e Taipas. Este projeto foi concebido a partir do programa de implantação de assentamentos, visando a fruticultura dele derivado com uma área de aproximadamente 5.000 ha voltada para a fruticultura irrigada.

O Projeto de piscicultura Tamborá, com força de polarização de toda a sua cadeia produtiva regional, apresentou para a região uma forte aptidão para a piscicultura. A criação de peixes é realizada através do sistema semi-intensivo, gerando bons resultados, e tem servido como demonstração para outros produtores da Região e do Estado. O Projeto Tamborá (abatedouro e frigorífico de peixes), em Almas, além de abastecer o mercado local, comercializa remessas de peixes para o mercado externo.

Além desses projetos, nos municípios de Dianópolis e Combinado, houve a introdução das frentes de agricultura comercial, que tem significado a implantação de sistemas de produção intensivos, utilizados no Estado, principalmente na cultura da soja. A cultura da soja tocantinense é uma das atividades que mais tem se desenvolvido no Sudeste.

\section{Índice FIRJAN de Desenvolvimento Municipal}

O Índice FIRJAN de Desenvolvimento Municipal (IFDM) é um estudo do Sistema FIRJAN, elaborado pela Federação das Indústrias do Estado do Rio de Janeiro em 2008. O índice tem por objetivo acompanhar o desenvolvimento socioeconômico de todos municípios brasileiros, abordando três áreas de atuação: Emprego \& renda, Educação e Saúde (FIRJAN, 2018). A base de dados utilizada para elaboração deste indicador se trata das estatísticas públicas oficiais, que são disponibilizadas pelos ministérios do Trabalho, Educação e Saúde, respectivamente.

Neste trabalho, foram analisados os valores do IFDM. Este índice possui vantagem em relação ao IDHM, pois é anual, ao passo que o outro, e a maioria dos índices deste segmento, é decenal, acompanhando os censos (CÓCARO et al., 2016). Além disso, a leitura deste índice é muito simples, pois varia de 0 (mínimo) a 1 ponto (máximo) e possibilita classificar o nível de cada município em quatro categorias: baixo (de 0 a 0,4$)$, regular $(0,4$ a 0,6$)$, moderado (de 0,6 a 0,8$)$ e alto $(0,8$ a 1$)$ desenvolvimento. Ou seja, quanto mais próximo de 1 , maior o desenvolvimento da localidade (FIRJAN, 2018).

O FIRJAN é subdividido em três eixos: emprego e renda, educação e saúde. Estão disponíveis para acesso dados nestes três eixos, além do IFDM geral. Nesse trabalho optou-se pelo uso do FIRJAN geral, pois já traz em si o somatório ponderado dos demais componentes. Além, disso este indicador possui periodicidade anual, o que o torna vantajoso (CÓCARO et al., 2016). Foi gerado um mapa com a distribuição espacial do IFDM entre os municípios da RID (Figura 07). 


\section{Resultados}

\section{Projetos de influência para a região}

No Tocantins, também se destaca o avanço no uso da terra por meio de plantações de Soja. E, ressalta-se que os produtores deste grão, no estado, correspondem a pequenos e médios agricultores, cujas áreas variam entre 500 e 1.000 ha. Constitui um grupo, que é composto, principalmente, de famílias oriundas do Sul do país e grupos empresariais (SEPLAN, 2015). Conforme Varanda (2017) os aspectos climáticos do Tocantins, possibilita a obtenção de sementes de boa qualidade da soja, proporcionando boa produtividade na safra e entressafra. Estes fatores, entre outros, são responsáveis por atrair agricultores interessados na implantação da soja no referido estado. E, a partir da década de 1970, cabe destacar que esta unidade federativa também ingressou na chamada fronteira agrícola, o que impulsionou a inserção de grandes projetos de irrigação, entre os quais, plantios de soja estavam inclusos (BARBOSA, 1996).

A expansão do setor agrícola, nesse caso, pode-se citar o aumento na produção de grãos (soja, milho), a produção de peixes, a fruticultura irrigada e a produção de canade-açúcar e álcool, após a implantação dos projetos de governo voltados para o desenvolvimento da agricultura na RID. Os dados de QL mostram que estas atividades não ocorrem de forma homogênea no espaço, fazendo com que os fluxos de renda e desenvolvimento estejam sendo completamente reordenados dentro da própria região.

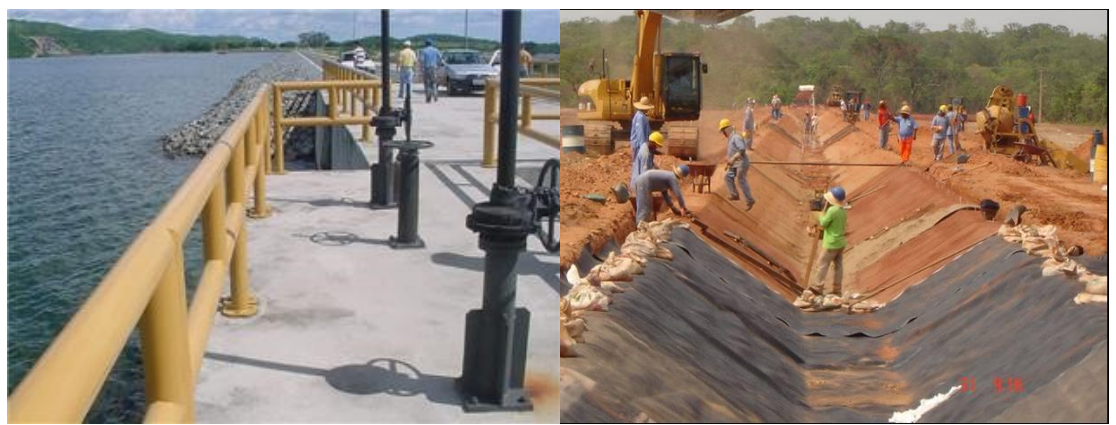

Figura 03: Canais de irrigação e da Barragem do Projeto Manuel Alves.

Fonte: SEPLAN (2007).

\section{Quociente Locacional ( $Q L)$ e seu reflexo na economia regional}

Dianópolis tem sido o município com maior diversidade em relação aos setores econômicos estudados, conforme mostra a figura 04. Este município demonstrou QL significativo em todas as atividades em 2016, exceto para as atividades de indústria extrativa mineral e administração pública. Este ente federativo figura com um dos lugares centrais, como preconizado por Christaller (1966). A indústria extrativa mineral concentrava-se em Rio da Conceição (NE) e Novo Jardim (E) em 2006, entretanto, 
passou a abranger também Arraias (SO) e Taguatinga (SE) em 2016, devido às reservas minerais de Calcário nestes municípios.

A indústria extrativa mineral tornou-se mais intensa na porção sudoeste $(\mathrm{SO})$ da área de estudo em 2016. Todavia, os municípios situados mais ao norte $(\mathrm{N})$ demonstram redução no quantitativo empregado nesse ramo de atividade. Esse resultado pode ser reflexo de mudanças governamentais (locais e macrorregionais), que incidiram sobre esses entes federativos nos anos de coleta dos dados. Por outro lado, a presença do Instituto Federal de Educação, Ciência e Tecnologia do Estado do Tocantins (IFTO) em Dianópolis, é, entre outros motivos, o responsável por esse município manter QL significativo para Serviços industriais de utilidade pública e Construção civil. Dessa forma, a porção nordeste (NE) da área de estudo se destacou nos dois ramos de atividade citados. Resultado similar foi encontrado por Fonseca e Aguiar (2019) pois, as instituições de ensino superior tendem a gerar concentração de renda em certas localidades.

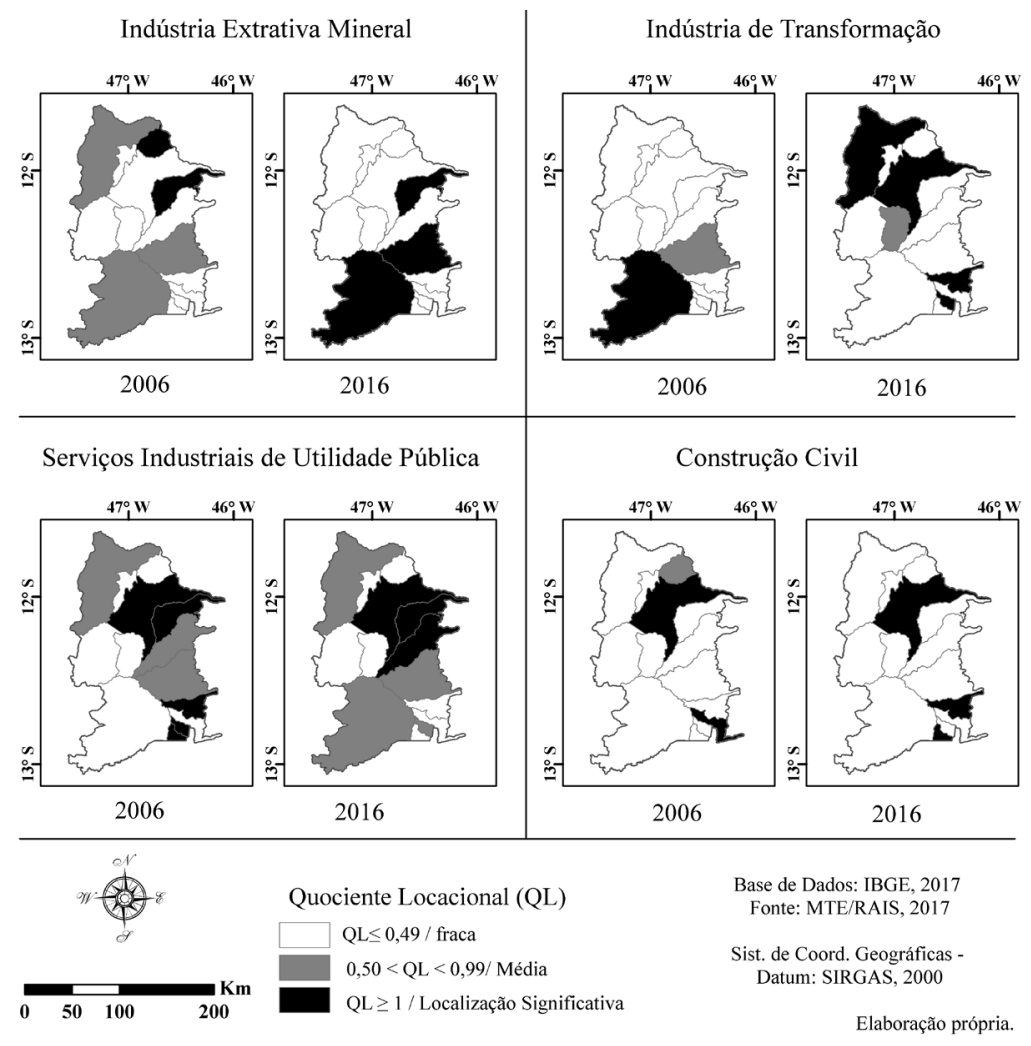

Figura 04: Resultados do QL para: indústria extrativa mineral; Indústria de transformação; Serviços industriais de utilidade pública e Construção civil. 
A construção civil, enquanto ramo de atividade econômica que depende, entre outros fatores, da dinâmica econômica local, manteve-se concentrada em Dianópolis (2006 e 2016) e Lavandeira (2006) e Aurora do Tocantins e Novo Alegre (2016). Este resultado pode refletir a situação econômica do Tocantins como um todo, bem como, a posição geográfica desta região imediata em relação a rodovia Transbrasiliana (BR 153), principal eixo de desenvolvimento do estado (OLIVEIRA e PIFFER, 2018). Para esses autores, as cidades mais próximas do "corredor de progresso" (BR 153), são privilegiadas pela localização (Figura 05), e por sua vez, dinamizam-se e e são reforçadas, diferente do sudeste do estado, área analisada neste trabalho. Entretanto, quanto ao setor da construção civil não se deve desconsiderar a existência de postos de trabalho informal, não contemplados pela RAIS. (Figura 06).

Novo Alegre e Dianópolis eram as únicas municipalidades que possuíam Q1 significativo para serviços em 2006. Em 2016, o quantitativo de ocupados neste setor expandiu-se para Arraias e Taguatinga. Tal resultado decorre do avanço da indústria extrativa mineral nestes dois últimos municípios. Nesse sentido, nota-se que o crescimento de uma atividade básica reflete no surgimento de uma outra, não básica (PIFFER, 2012). Para este autor as básicas são aquelas atividades motoras, que conseguem multiplicar empregos e investimentos (p. 51). Uma vez que a expansão de atividades de base resulta em avanço no setor de serviços (conforme os resultados para Taguatinga e Arraias), dinamizando a economia urbana em seu conjunto (PIFFER, 2012).

Para o ano de 2006, observou-se que apenas Almas, Autora do Tocantins e Novo Alegre possuíam QL significativo em relação à agropecuária. Por outro lado, 10 $(71,4 \%)$ dos 14 municípios possuíam QL significativo para Administração Pública em 2006, alterando-se para e $11(78,6 \%)$ em 2016. O desempenho locacional aponta para o avanço das atividades agropecuárias em $50 \%$ dos municípios desta região imediata em 2016. O QL elevado para este setor em 2016 pode refletir os impactos positivos do projeto de irrigação rio Manoel Alves (implantado na porção norte da área de estudo), inaugurado em 2008. Como pontuam Oliveira e Rodrigues (2017), este projeto buscou dinamizar a economia da região imediata de Dianópolis, por meio do aumento da atividade agrícola, ofertando trabalho e renda. 


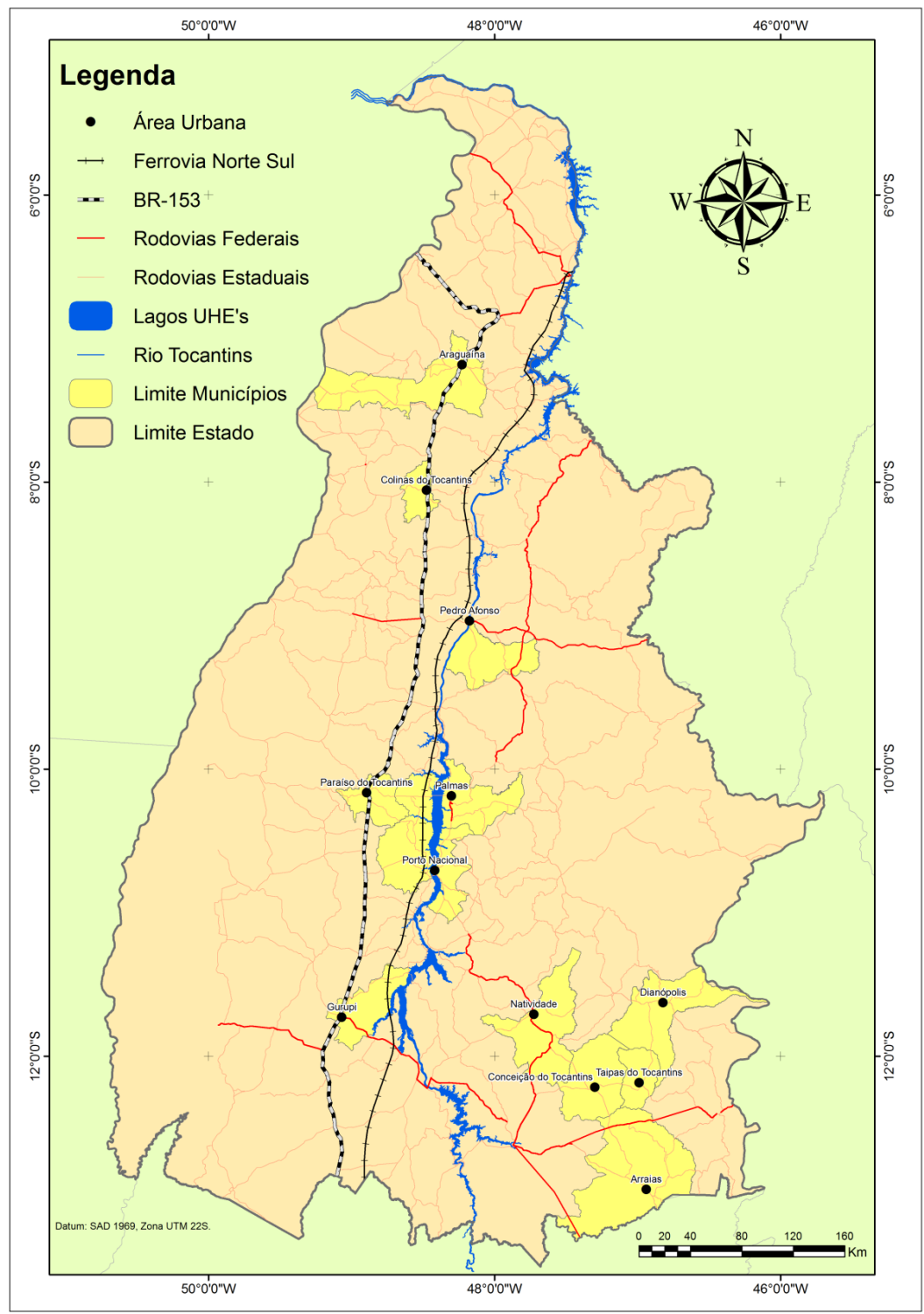

Figura 05: Principais modais de transportes do território Estado do Tocantins - a BR-153, Rio Tocantins e a Ferrovia Norte-Sul.

Fonte: adaptado da Base Cartográfica da Seplan - TO, (2015). 


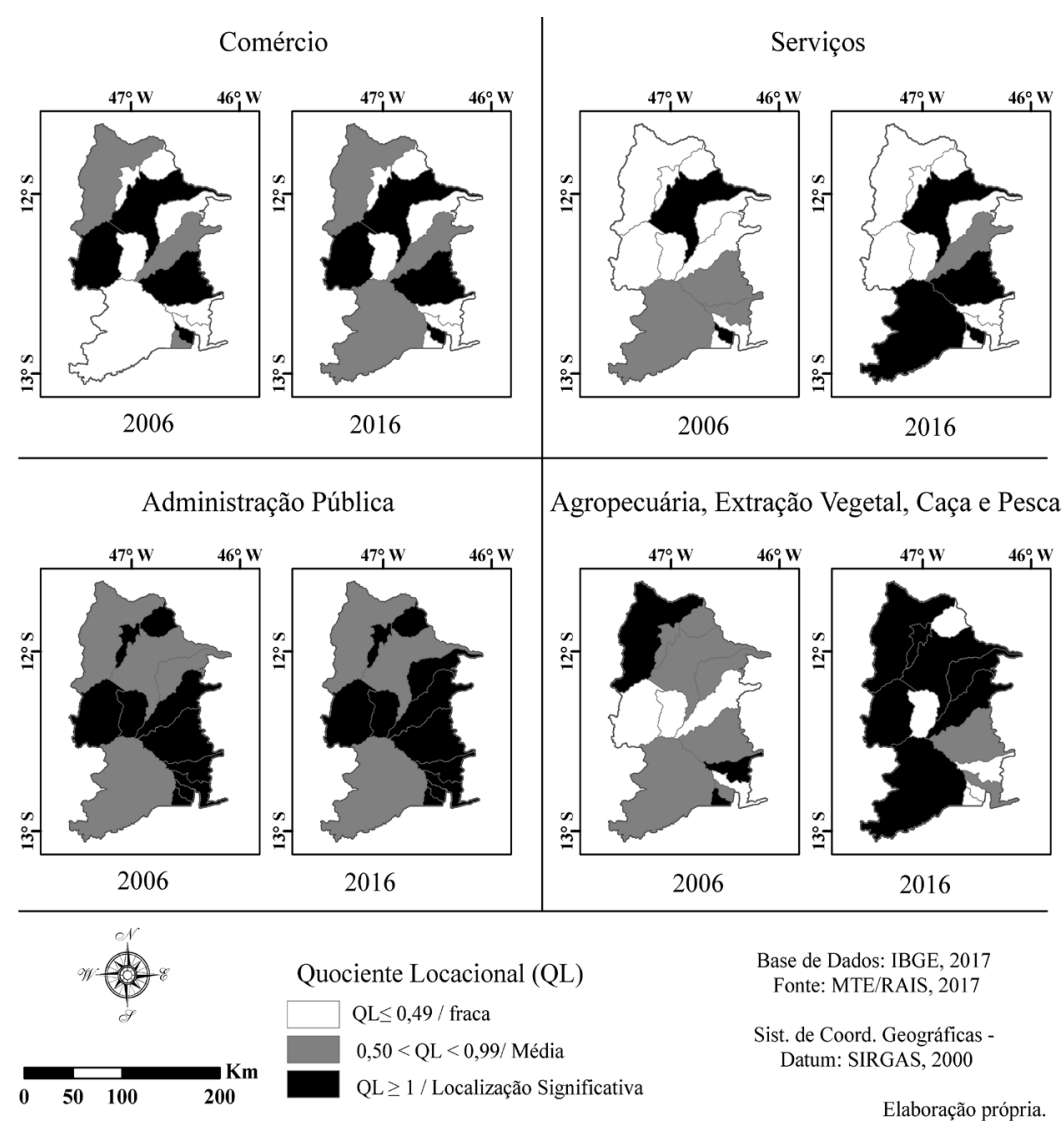

Figura 06: Resultados do QL para: Comércio; Serviços; Administração pública e Agropecuária, extração vegetal, caça e pesca.

Para que a região expanda suas atividades produtivas de base econômica, como apregoa a teoria de North (1977), faz se necessária a modernização da agropecuária, a qual demanda mão de obra qualificada, modernas técnicas de manejo do solo, utilização de maquinário agrícola, equipamentos e assistência de acompanhamento na extensão rural. Dessa forma a RID possibilitará a geração de novos postos de trabalho e renda. Para suprir essa demanda espera-se que instituições de ensino superior implantadas na RID, possa cumprir esse papel.

O ramo de atividade comércio apresentou distribuição espacial irregular nos dois anos analisados. Há municípios nas porções Nordeste (NE), Oeste (O), Sudeste (SE) e Sul (S) da área de estudo com QL significativo. Para o ramo de serviços, a distribuição espacial das municipalidades com QL significativo ocorreu entre as áreas a NE e S, em 2006; e com distribuição espacial irregular em 2016. Destaca-se que esse resultado está 
diretamente relacionado com a presença do IFTO em Dianópolis (NE), e da Universidade Federal do Tocantins (UFT) em Arraias, porção SO da RID.

Quanto ao ramo da Administração pública, em que nenhum dos entes federativos apresentaram QL na faixa de localização fraca, cabe ressaltar que esse é um resultado negativo do ponto de vista econômico. Tal resultado aponta para a concentração de insivíduos ocupados neste ramo de atividade em toda a RID, de modo que a presença do IFTO ou da UFT, ainda não foi capaz de solucionar esse impasse regional, embora contribuiu para o avanço de outros ramos (Serviços, por exemplo). E, a maior quantidade de municípios, com altos valores de QL estão localizadas na porção Leste (E) e SE, contudo, a distribuição espacial permaneceu irregular.

Para o ramo de atividade Agropecuária, Extração Vegetal, caça e pesca os municípios com QL significativo encontram-se espacialmente dispersos na porção estudada. Os resultados de 2006, mostram entes federativos nas áreas a Noroeste (NO), SE e S; para 2016, nas porções SO, O, NO, e NE (excetuando-se, o município de Rio da Conceição, que apresentou QL na faixa fraca). Isso significa que a maioria das municipalidades passaram a apresentar um aumento significativo de empregados nesse ramo de atividade, o que figura como redução do desemprego nesses territórios.

\section{Indicador de desenvolvimento municipal - FIRJAN}

Os resultados do índice FIRJAN mostram que estes municípios encontram-se entre o desenvolvimento moderado $(0,600$ - 0,800) e regular $(0,400$ - 0,600). Destaca-se uma alteração norte-sul em relação aos municípios com desenvolvimento moderado (Arraias, Novo Alegre, Combinado e Taipas do Tocantins) em 2006 estavam nesta situação (Figura 07). Entretanto, em 2016, os municípios do norte da área de estudo (Almas, Porto Alegre e Rio da Conceição) mostraram-se com desenvolvimento moderado segundo os resultados deste índice. A exceção é Dianópolis (NE), que tanto em 2006 quanto 2016 esteve classificado como moderado no IFDM.

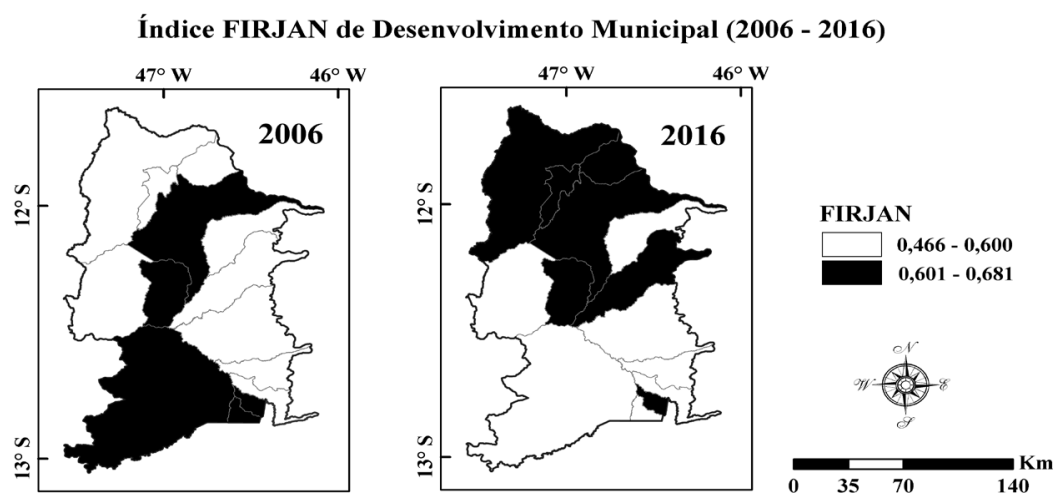

Figura 07: IFDM dos municípios da RID.

Fonte: Elaboração própria com dados do FIRJAN (2018). 
Cabe destacar que nenhum ente federativo apresentou FIRJAN baixo $(\leq 0,400)$ ou alto $(\geq 0,800)$. Uma vez que este índice considera os eixos emprego e renda, educação e saúde (FIRJAN, 2018) seus resultados pontuam avanços socioeconômicos significativos em nível municipal. Salienta-se ainda que, no Tocantins apenas Palmas atingiu alto desenvolvimento $(0,801)$ para o referido índice em 2016. Nem Gurupi $(0,777)$ nem Araguaína $(0,776)$ atingiram tal magnitude. $\mathrm{O}$ avanço que ocorreu em Porto Alegre do Tocantins (de 0,495 para 0,680 em 2016) e Rio da Conceição (de 0,488 para 0,660) em relação ao FIRJAN pode resultar da implementação do projeto Manoel Alves no rio homônimo, o qual estaria beneficiando municípios próximos à Dianópolis, sede do projeto.

Os resultados dos IFDM moderado, na RID, podem ser considerados em função da falta de acesso a técnicas eficientes de manejo do solo do Cerrado e a escassez de crédito. Tais fatores impossibilitam os pequenos produtores agrícolas, de gerar um excedente, capaz de expandir o seu ciclo produtor além do necessário à sua subsistência e à manutenção (estagnada) das suas condições de produção. Em grande medida, os mais pobres acabam se desfazendo de suas terras e indo, normalmente, em direção às cidades. Associado a este quadro está a pressão exercida pela expansão do agronegócio em grande escala, que concentra terras e renda.

\section{Considerações Finais}

A partir do exposto notou-se que a RID possui características próprias em relação ao desenvolvimento regional. Neste recorte geográfico, a administração pública ocupa lugar de destaque em relação ao quantitativo de empregos formais, posto que 78,5\% destes municípios apresentaram QL significativo em 2016.

O setor agropecuário, subsidiado pelos projetos de irrigação, mostrou grande avanço em relação ao período analisado. Em 2006, somente 21,4\% dos municípios apresentaram QL significativo. Ou seja, havia poucos municípios com altos quantitativos de pessoal empregado nesta atividade. Embora 42,8\% destes entes federativos demonstraram QL médio. Todavia, em 2016, 50\% destas municipalidades mostraram-se significativas para agropecuária e 14,2\% apresentaram QL médio.

A relação entre ocupados na agropecuária, em empregos formais, sinaliza o impacto positivo do projeto Manoel Alves na RID. Por outro lado, o IFDM, que mostrava-se moderado somente em municípios ao sul da RID (Arraias, Novo Alegre, Combinado e Taipas do Tocantins) alterou toda a sua configuração, ou seja, estes deixaram sua posição relativa ao FIRJAN. Logo, tais municípios passaram a ocupar desenvolvimento regular. A exceção é Dianópolis, que nos dois períodos analisados, manteve-se com desenvolvimento moderado. Já os municípios do norte da RID foram atingidos positivamente pela implantação do projeto de irrigação supracitado. 
Além disso, a presença de instituições de ensino superior em Dianópolis e Arraias, por sua vez fazem destes municípios pólos ou centros regionais. Dão-lhes aparato para se manter com uma tendência ao desenvolvimento maior em relação aos municípios da RID, configurando como um lugar central entre os demais. Dianópolis possui, por sua vez maior diversidade em relação ao número de ocupados nas variadas atividades econômicas.

Os índices de QL e IFDM encontrados na RID apresentam diferentes taxas de desenvolvimento, isso se deve em suma, as diferentes características de cada município, como o caso dos entes federativos ao norte da RID que não acompanharam o desenvolvimento que vem ocorrendo na região sudeste.

Recomenda-se que o governo local, juntamente com as instituições fortaleça as relações de governança, implementando pequenas ações, como: crédito, assistência técnica, capacitação dos atores locais (micro empreendedor, pequeno produtor rual, servidores públicos, secretários e prefeitos). Além disso, que estabeleça um diálogo permanente com a sociedade na promoção do desenvolvimento regional e local.

Para trabalhos futuros, recomenda-se a utilização de outros métodos de ánalise regional, como: multiplicador de emprego, associação geográfica e método estruturaldiferencial, entre outros, bem como, expandir a análise para outras regiões do Tocantins.

\section{Referências}

ALVES, L. R. Indicadores de localização, especialização e estruturação regional. IN: PIACENTI, C. A.; FERRERA DE LIMA, J. (Orgs.). Análise regional: metodologias e indicadores. Curitiba: Camões, 2012.

BARBOSA, Y. M. Conflitos Sociais na Fronteira Amazônica: o Projeto Formoso. Campinas/SP. Papirus, 1996. 120p

BEGNINI; S.; ALMEIDA, L. E. D. F. Grau de desenvolvimento regional dos municípios da mesorregião oeste catarinense: caracterização e classificação. Revista Internacional de Desenvolvimento Local. Campo Grande, MS, vol. 17. Nº.04, p, 547$560,2016$.

BRASIL. Ministério do Trabalho e Emprego. Relatório Anual de Informações Sociais. Disponível: $<$ http://bi.mte.gov.br/bgcaged/caged_rais_vinculo_id/caged_rais_vinculo_ba sico_tab.php>. Acesso em: 15 dez. 2016.

CARVALHO, W.Q.: OLIVEIRA, N. M.; LUZ, R. A. (2018). Análise locacional das atividades produtivas na microrregião de porto nacional do estado do Tocantins.

Economia \& Região, v. 6, p. 47, 2018.

CHRISTALLER, W. Central Places in Southern Germany. Translated by Carlisle W. Baskin. Pp. 230. Englewood Cliffs, N.J.: Prentice-Hall, 1966. 
CÓCARO, H.; CARDOSO, R. F.; PEREIRA, J. R. (2016). Territórios da Cidadania do estado de Mato Grosso: uma avaliação socioeconômica utilizando o índice FIRJAN. Interações, v. 17, p. 193-209, 2016.

FEDERAÇÃO DAS INDÚSTRIAS DO ESTADO DO RIO DE JANEIRO (FIRJAN). Índice Firjan de Desenvolvimento Municipal - IFDM. Disponível em: $<$ http://www.firjan.com.br/ifdm/downloads/>. Acessado aos 17/08 de 2018.

FONSECA, S. F.; MENDONCA, G. L.; HERMANO, V. M.; SILVA, A. C. Análise da pobreza e desenvolvimento humano na microrregião de Diamantina/MG, Brasil, usando técnicas de geoprocessamento. Revista Geográfica Acadêmica, v. 10, p. 164-179. 2016.

FONSECA, S. F.; AGUIAR, H. H. Identificação de Cluster de concentração de renda e dependência demográfica nos Vales do Jequitinhonha e Mucuri. RA'EGA: Espaço Geográfico em Análise, v. 46, p. 132-144, 2019

GUIMARÃES NETO, Leonardo. Dinâmica recente das economias regionais brasileiras. Revista Paranaense de Desenvolvimento, Curitiba, n. 86, p. 123-152, set./dez. 1995.

INSTITUTO BRASILEIRO DE GEOGRAFIA E ESTATÍSTICA - (IBGE). Divisão Regional do Brasil em Regiões Geográficas Imediatas e regiões Geográficas Intermediárias. Coordenação de Geografia. - Rio de Janeiro: IBGE. 2017. 82p.

ISARD, W. Methods of Regional Analysis: an Introduction to Regional Science. M.I.T. Press. Cambridge, Massachusetts. 1960.

LOPES, A. S. Desenvolvimento Regional: Problemática, Teoria, Modelos. 2a ed. Lisboa: Fundação Calouste Gulbenkian, 1984. 384p.

NORTH, D. A agricultura no crescimento econômico. In: SCHWARTZMAN, J. (Org.). Economia regional: textos escolhidos. Belo Horizonte, MG: CEDEPLAR/CETEDRE MINTER, p. 333-343, 1977.

OLIVEIRA, N. M.; PIFFER, M. Determinantes do Perfil Locacional das atividades produtivas no Estado do Tocantins. Boletim de Geografia (UEM), v. 36, p. 92-111, 2018.

OLIVEIRA, T. J. A.; RODRIGUES, W. Planejamento Espacial e o Projeto de Irrigação Manoel Alves. Revista Brasileira de Assuntos Regionais e Urbanos. Goiânia, v. 3, n. 2, p. 173-190, jul./dez. 2017

OLIVEIRA, N. M.; BRITO, E. P.; MEDEIROS, M. R. Universidade Federal do Tocantins - UFT e sua Inserção Regional: uma abordagem da Teoria dos Lugares Centrais. Interface (Porto Nacional), v. Maio/13, p. 1-10, 2013.

PIFFER, M. Indicadores de base econômica. PIACENTI, C.; FERRERA DE LIMA, J. IN: Análise Regional: Indicadores e Metodologias. Curitiba: Camões, p. 51-62, 2012

SCHEER, M. A. P. S. et al. Geoprocessamento como estratégia de investigação do espaço geográfico: uma abordagem socioambiental aplicada ao Território de Identidade 
Sertão do São Francisco (BA), 2004 a 2006. Projeto de Pesquisa (Mestrado em Geografia) - Departamento de Geografia/Instituto de Geociências, Universidade Federal da Bahia, Bahia, 2008. 12 f.

SEN, A. Desenvolvimento como liberdade. São Paulo: Companhia das Letras, 2010.

Secretaria do Planejamento e Orçamento (SEPLAN). Governo do Estado do Tocantins. O perfil do Agronegócio Tocantinense. Relatório Final. 2015, 139p.

Secretaria do Planejamento e Orçamento (SEPLAN). Governo do Estado do Tocantins. Relatórios Técnicos Sobre Desenvolvimento no Tocantins. Relatório Final. 2017

SIEDENBERG, D. R. Indicadores de desenvolvimento socioeconômico: uma síntese. Desenvolvimento em Questão. Vol. 01, nº 01, Jan/Jul. pp. 45-71. 2003.

STRASSBURG, U.; DE LIMA, J. F.; OLIVEIRA, N. M. A centralidade e o Multiplicador de Emprego: Um estudo sobre a Região Metropolitana de Curitiba. URBE. Revista Brasileira de Gestão Urbana, v. 6, p. 218-235, 2014.

VARANDA, M. A. F. Influência do boro via aplicação foliar em soja na várzea irrigada no Tocantins. Disserteção (Mestrado em Produção Vegetal) Programa de Pósgraduação em Produção Vegetal. Universidade Federal do Tocantins (UFT), Gurupi/TO. 2017.

Agradecimentos: O presente trabalho foi realizado com apoio da Coordenação de Aperfeiçoamento de Pessoal de Nivel Superior - Brasil (CAPES) - Código de Financiamento 001. Os autores agradecem a CAPES pela bolsa de pesquisa do segundo autor e, ao parecerista pelas excelentes sugestões.

Roberta Mara de Oliveira Vergara

Doutoranda em Desenvolvimento Regional pela Universidade Federal do Tocantins (PGDR/UFT) - Câmpus Palmas. Mestre em Engenharia e Meio Ambiente pela Universidade Federal de Goiás. Graduada em Geoprocessamento pelo Instituto Federal do Goiás. Professora do curso de Engenharia Civil na Universidade Federal do Tocantins. Quadra 109 Norte. Avenida NS 15 - Predio da Engenharia Civil, Laboratório de Modelagem Numérica. Plano Diretor Norte. CEP: 77001-090 - Palmas, TO - Brasil

E-mail: robertaoliveira@mail.uft.edu.br

Samuel Ferreira da Fonseca

Doutorando em Desenvolvimento Regional pela Universidade Federal do Tocantins (PGDR/UTF) - Câmpus Palmas. Mestre em Produção Vegetal pela Universidade Federal dos Vales do Jequitinhonha e Mucuri. Graduado em Geografia pela Universidade Estadual de Montes Claros. Bolsista da Coordenação de Aperfeiçoamento de Pessoal de Nível Superior - CAPES. Quadra 109 Norte. Avenida NS 15 - Predio do PGDR. Plano Diretor Norte. CEP: 77001-090 - Palmas, TO - Brasil.

E-mail: fonsekageo@gmail.com 


\section{Nilton Marques de Oliveira}

Economista, Doutor em Desenvolvimento Regional e Agronegócio (UNIOESTE).

Professor do Programa de Pós-Graduação em Desenvolvimento Regional e do Curso de Ciências Econômicas (PGDR/UFT). Líder do Grupo de Pesquisa em Desenvolvimento Regional e Territorial do Centro Norte do Brasil - DRT Centro Norte (CNPq/UFT). Av. NS 15 ALC NO 14, Prédio do PPGDR |77001-090| Palmas/TO (63) 3232-8224

E-mail-niltonmarques@uft.edu.br

Recebido para publicação em março de 2019 Aprovado para publicação em outubro de 2019 